\title{
Insulin-Degrading Enzyme as a Downstream Target of Insulin Receptor Signaling Cascade: Implications for Alzheimer's Disease Intervention
}

\author{
Lixia Zhao, ${ }^{1,3}$ Bruce Teter, ${ }^{1,3}$ Takashi Morihara, ${ }^{1,3}$ Giselle P. Lim, ${ }^{1,3}$ Surendra S. Ambegaokar, ${ }^{1,3}$ Oliver J. Ubeda, ${ }^{1,3}$ \\ Sally A. Frautschy,,$^{1,2,3}$ and Greg M. Cole ${ }^{1,2,3}$ \\ Departments of ${ }^{1}$ Medicine and ${ }^{2}$ Neurology, University of California Los Angeles, and ${ }^{3}$ Geriatric Research Education and Clinical Center and Greater Los \\ Angeles Healthcare System, North Hills, California 91343
}

\begin{abstract}
Insulin-degrading enzyme (IDE) is one of the proteins that has been demonstrated to play a key role in degrading $\beta$-amyloid (A $\beta$ ) monomer in vitro and in vivo, raising the possibility of upregulating IDE as an approach to reduce A $\beta$. Little is known, however, about the cellular and molecular regulation of IDE protein. Because one of the main functions of IDE is to degrade insulin, we hypothesized that there is a negative feedback mechanism whereby stimulation of insulin receptor-mediated signaling upregulates IDE to prevent chronic activation of the pathway. We show that treatment of primary hippocampal neurons with insulin increased IDE protein levels by $\sim 25 \%$. Insulin treatment also led to phosphatidylinositol-3 (PI3) kinase activation evidenced by Akt phosphorylation, which was blocked by PI3 kinase inhibitors, wortmannin and LY 294002. Inhibition of PI3 kinase abolished the IDE upregulation by insulin, indicating a causeeffect relationship between insulin signaling and IDE upregulation. Further support for this link was provided by the findings that deficient insulin signaling (decreased PI3 kinase subunit P85) was correlated with reduced IDE in Alzheimer's disease (AD) brains and in Tg2576 Swedish amyloid precursor protein transgenic mice fed a safflower oil-enriched ("Bad") diet used to accelerate pathogenesis. Consistent with IDE function in the degradation of $A \beta$ monomer, the IDE decrease in the Bad diet-fed Tg2576 mice was associated with increased $\mathrm{A} \beta$ monomer levels. These in vitro and in vivo analyses validate the use of enhanced CNS insulin signaling as a potential strategy for $\mathrm{AD}$ intervention to correct the IDE defects occurring in AD.
\end{abstract}

Key words: insulin; insulin-degrading enzyme; hippocampal neurons; Alzheimer’s disease; Tg2576 transgenic mice; PI3 kinase

\section{Introduction}

Insulin-degrading enzyme (IDE), a metalloprotease enzyme responsible for insulin degradation, has been demonstrated to play a key role in $\beta$-amyloid $(\mathrm{A} \beta$ ) peptide degradation both in vitro and in vivo and is selective for $\mathrm{A} \beta$ monomer (Vekrellis et al., 2000; Farris et al., 2003, 2004). Genetic linkage studies have linked Alzheimer's disease $(\mathrm{AD})$ and plasma $\mathrm{A} \beta 42$ levels to chromosome 10q, which harbors the IDE gene (Bertram et al., 2000; ErtekinTaner et al., 2000). Subsequent genetic studies established a direct linkage of genetic variants in a haplotype block-spanning IDE to increased plasma $\mathrm{A} \beta 42$ levels and risk of $\mathrm{AD}$ (Ertekin-Taner et al., 2004). IDE has been observed in human CSF, and its activity, levels, and mRNA are decreased in AD brain tissue and associated with increased $A \beta$ levels (Cook et al., 2003). The regulation of IDE levels, however, is essentially unknown.

Received July 15, 2004; revised 0ct. 17, 2004; accepted Nov. 2, 2004.

This work was supported by National Institutes of Health Grants R01 AG13471 (G.M.C.) and R01 AG16793 (S.A.F.) and University of California Los Angeles Alzheimer's Disease Research Center (UCLA ADRC) Grant P50 AG16570 (G.M.C., S.A.F.). AD brain tissue samples were obtained in part from the University of Southern California Neuropathology Core of the ADRC (C. A. Miller, P50 AG05142) and the Neuropathology and Molecular Genetics Core of the UCLA ADRC (P50 AG 16570)

Correspondence should be addressed to Dr. Greg M. Cole, Greater Los Angeles Healthcare System Veterans Administration Medical Center, 16111 Plummer Street, Building 7, Room A102, North Hills, CA 91343. E-mail: gmcole@ucla.edu.

DOI:10.1523/JNEUROSCI.2860-04.2004

Copyright $\odot 2004$ Society for Neuroscience $\quad 0270-6474 / 04 / 2411120-07 \$ 15.00 / 0$
The recent rise in interest in insulin signaling and its relationship with $\mathrm{AD}$ is driven to a large extent by the increasing number of prospective and retrospective epidemiological findings, which indicate that type II diabetes mellitus is a significant risk factor for developing AD (Ott et al., 1996, 1999; Leibson et al., 1997). Type II diabetes mellitus is characterized by insulin resistance, reduced insulin secretion, and overt hyperglycemia (Olson and Norris, 2004). The enhanced risk for developing AD in diabetic patients remains strong even when vascular factors are controlled, suggesting a nonvascular mechanism for diabetes-related $\mathrm{AD}$ pathogenesis (Peila et al., 2002).

The relationship between diabetes mellitus and $\mathrm{AD}$ is particularly intriguing given the finding that $\mathrm{AD}$ patients have lower CSF insulin levels and reduced insulin-mediated glucose disposal when compared with healthy control subjects (Craft et al., 1998, 2003). This parallel decrease of insulin and its degrading enzyme IDE in AD raises the possibility that insulin might normally upregulate IDE in the brain via a negative feedback control mechanism to limit the insulin response. Also, unlike peripheral insulin receptors, insulin receptors in the brain are not downregulated by high concentrations of insulin (Boyd and Raizada, 1983; Zahniser et al., 1984), leaving IDE as a plausible effector molecule with upregulation that could turn off insulin signaling in the presence of high insulin levels. Consistent with this hypothesis, a recent report by Ho et al. (2004) showed that insulin-resistance caused 
by a high-fat diet is associated with reduced IDE levels and increased amyloidosis in an AD animal model.

To test the hypothesis that insulin might upregulate IDE via a negative feedback control mechanism, we used both in vitro and in vivo strategies to determine the impact of insulin signaling on IDE levels. Results obtained from primary hippocampal neurons, AD brains, and Tg2576 mice fed a safflower oil-enriched "Bad" diet establish a causal relationship between insulin signaling and IDE. Results from this study provide the first documentation of IDE regulation by insulin signaling and suggest that enhancement of the CNS insulin signaling cascade could be used as a potential therapeutic strategy for AD.

\section{Materials and Methods}

Primary hippocampal neuronal culture. Use of animals was approved by the Greater Los Angeles Veterans Administration Institutional Animal Care and Use Committee and University of California Los Angeles Chancellor's Animal Research Committee (Protocol No. 9804-014). Primary cultures of hippocampal neurons were prepared as described previously (Zhao et al., 2003). Briefly, hippocampi were dissected from the brains of embryonic day 18 (E18) Sprague Dawley rat fetuses, treated with $0.05 \%$ trypsin in HBSS for $5 \mathrm{~min}$ at $37^{\circ} \mathrm{C}$, and dissociated by repeated passage through a series of fire-polished constricted Pasteur pipettes. For immunocytochemical staining analyses, between 20,000 and 40,000 cells were seeded onto poly-D-lysine $(10 \mu \mathrm{g} / \mathrm{ml})$-coated 8 -well chamber slides, and cultures used for Western immunoblotting and lactate dehydrogenase (LDH) analyses were plated onto poly-D-lysine-coated 6-well plates at a density of $10^{6}$ neurons per well. Nerve cells were grown in phenol red-free Neurobasal medium (NBM; Invitrogen, Carlsbad, CA) supplemented with B27, $5 \mathrm{U} / \mathrm{ml}$ penicillin, $5 \mu \mathrm{g} / \mathrm{ml}$ streptomycin, $0.5 \mathrm{~mm}$ glutamine, and $25 \mu \mathrm{m}$ glutamate, at $37^{\circ} \mathrm{C}$ in $10 \% \mathrm{CO}_{2}$. Cultures grown in serum-free NBM yielded $\sim 99.5 \%$ neurons and $0.5 \%$ glia. Microscopically, glial cells were not apparent in hippocampal cultures at the time they were used for experimental analyses. The culture media were exchanged with glutamate-free NBM $3 \mathrm{~d}$ after the day of cell culture. Hippocampal neurons, 7-10 d old, were then treated with insulin and/or other pharmacological agents for $24 \mathrm{hr}$ in NBM without B27 supplement.

Cell lysate preparation from hippocampal neurons. Treated neurons were washed with cold PBS once and scraped off the dish into $1 \mathrm{ml}$ of PBS. Cells were then centrifuged at $5000 \mathrm{rpm}$ for $5 \mathrm{~min}$, and the pellets were dissolved in the lysis buffer $\left(150 \mathrm{~mm} \mathrm{NaCl}, 10 \mathrm{~mm} \mathrm{NaH}_{2} \mathrm{PO}_{4}, 1 \%\right.$ Triton X-100, $0.5 \%$ SDS, $0.5 \%$ deoxycholate, and a mixture of protease and phosphatase inhibitors) and suspended by brief sonication. After incubation at $4^{\circ} \mathrm{C}$ for $30 \mathrm{~min}$, the samples were centrifuged at $12,000 \mathrm{rpm}$ for $10 \mathrm{~min}$, and the supernatants were collected as the neuronal protein extracts.

Animals and diet. Male and female Tg2576 transgenic mice, 17-19 months old, were randomly split into two treatment groups. For $103 \pm$ $5 \mathrm{~d}$, mice were fed a control standard diet (PMI 5015, PMI International LabDiet, St. Louis, MO) or a safflower oil-based diet (Bad diet; TD 00522, Harlan Teklad, Madison, WI) that is known to accelerate AD-like pathogenesis. The two diets were matched for equivalent protein, carbohydrate, minerals, and vitamins. Our safflower oil-enriched Bad diet is different from the diet used in many high-fat (60\% fat) studies in that the total fat content in the Bad diet is lower, in fact, than that in the standard diet ( $11 \%$ in the standard diet, $6 \%$ in the Bad diet). In the Bad diet, there is a near depletion of $n-3$ polyunsaturated fatty acid, and therefore there is a high ratio (85:1) of n-6 to $n-3$ polyunsaturated fatty acid in the Bad diet compared with the ratio of 7:1 in the standard diet. Animals were killed at 22 months of age.

Tissue preparation. Animals were perfused with $0.9 \%$ normal saline followed by HEPES buffer, $\mathrm{pH} 7.2$, containing a mixture of protease and phosphatase inhibitors. Brain regions were dissected from one hemisphere as described previously (Lim et al., 2001). Tissue samples from entorhinal cortex were homogenized in 10 wet weight volumes of TBS, pH 8.0, containing a mixture of protease and phosphatase inhibitors. Samples were sonicated briefly and centrifuged at $100,000 \times g$ for $20 \mathrm{~min}$ at $4^{\circ} \mathrm{C}$. The supernatant was collected as the TBS fraction. The pellets were redissolved in lysis buffer containing a mixture of protease and phosphatase inhibitors. Samples were sonicated briefly again and centrifuged at $100,000 \times g$ for $20 \mathrm{~min}$ at $4^{\circ} \mathrm{C}$. The resultant supernatant was collected as the lysis fraction.

Handling of human tissue. Postmortem tissue from temporal cortex and hippocampus was obtained from the University of Southern California and the University of California Los Angeles Alzheimer's Disease Research Center Pathology Cores. Controls (15-20) were compared with 15-20 AD patients with moderate disease. The age of death, gender, and postmortem interval were comparable in both groups. Specifically, the age of death of the AD subjects ranged between 63 and 97 years, with an average age of $83.33 \pm 1.97$ years. This was not significantly different from the cognitively normal group, which ranged from 62 to 95 years and averaged $81.69 \pm 2.91$ years. The gender was balanced, with $44 \%$ male and $56 \%$ female for the $\mathrm{AD}$ and $54 \%$ male and $46 \%$ female for the cognitively normal subjects. The postmortem interval ranged from 3.5 to $15 \mathrm{hr}$, with an average of $7.85 \pm 1.08 \mathrm{hr}$ for the $\mathrm{AD}$, and from 1.5 to $19 \mathrm{hr}$, with an average of $7.74 \pm 1.29 \mathrm{hr}$ for the cognitively normal group, again not significantly different. The human tissue was frozen before being homogenized and processed for protein measurement, and it was processed using a similar method as for mouse tissue.

Western immunoblotting. Protein concentration was determined by the Bio-Rad (Hercules, CA) DC protein assay. An appropriate volume of $5 \times$ sample buffer was added to the protein samples, which were then boiled at $100^{\circ} \mathrm{C}$ for $3 \mathrm{~min}$. Except for $\mathrm{A} \beta$ Western detection, samples ( 35 $\mu \mathrm{g}$ of proteins per well) were loaded on $10 \%$ Tris-glycine gels and resolved by standard electrophoresis at $12 \mathrm{~mA}$. Proteins were then electrophoretically transferred to Immobilon-P polyvinylidene difluoride (PVDF) membranes for $3.5 \mathrm{hr}$ at $400 \mathrm{~mA}$. For $\mathrm{A} \beta$ species separation, the protein samples were resolved on $10-20 \%$ Tris-Tricine gradient gels at $150 \mathrm{~mA}$ and transferred to Immobilon-P PVDF membranes for $2 \mathrm{hr}$ at 40 $\mathrm{mA}$. Membranes were blocked for $1 \mathrm{hr}$ at room temperature in $10 \%$ nonfat dried milk in PBS and then incubated overnight at $4^{\circ} \mathrm{C}$ with appropriate primary antibodies in PBS containing $0.05 \%$ Tween 20 (PBS-T) and $1.5 \%(\mathrm{w} / \mathrm{v})$ albumin. After they were rinsed in PBS-T, the membranes were incubated with horseradish peroxidase-conjugated anti-mouse IgG $(1: 10,000)$ or anti-rabbit IgG $(1: 30,000)$ in PBS-T with $1.5 \%$ albumin for $1 \mathrm{hr}$. Immunoreactive bands were visualized by ECL Western detection reagents and quantified using densitometric software (Molecular Analyst II, Bio-Rad, Richmond, CA). After transfer, gels were stained with Coomassie blue to ensure equal protein loading.

$L D H$ release analysis. $\mathrm{LDH}$ release into the culture media was measured using a CytoTox 96 Non-Radioactive Cytotoxicity Assay (Promega, Madison, WI), and absorption was read at $490 \mathrm{~nm}$.

Immunocytochemical staining. Hippocampal neurons were cultured on poly-D-lysine-coated 8-well chamber slides for 7-10 d before experimental treatments. After treatment, the slides were washed briefly with PBS and then fixed with $95 \%$ methanol at $4^{\circ} \mathrm{C}$. Nonspecific antibody binding was blocked by incubation in the blocking buffer (containing 3\% goat serum, $10 \%$ horse serum, $0.3 \%$ Triton X-100 in PBS) for 30 min at room temperature. The slides were then incubated with appropriate primary antibodies against IDE (rabbit polyclonal, 1:500) or phosphorylated-Akt (rabbit polyclonal, 1:500) at temperatures and times specified by the antibody providers. All primary antibodies were dissolved in PBS. After they were washed with PBS, the slides were incubated in anti-rabbit IgG secondary antibody conjugated with FITC (1:250; Vector Laboratories, Burlingame, CA) for $30 \mathrm{~min}$. The secondary antibody was also dissolved in PBS. The slides were washed extensively with PBS and coverslipped with $4^{\prime}, 6^{\prime}$-diamidino-2-phenylindole (DAPI)-containing mounting medium (Vector Laboratories) and viewed under a fluorescent microscope. Images of immunocytochemically stained hippocampal neurons were assembled into montages using Adobe Photoshop. NIH Image software was used to quantify the fluorescence levels.

Real-time PCR for IDE and $p 85$ mRNA. Total RNA was prepared using RNAqueous kits (Ambion, Austin, TX). The absence of RNA degradation was confirmed by gel electrophoresis, and total RNA was DNase treated (DNA-free; Ambion). cDNA was generated from $1.4 \mu \mathrm{g}$ of total RNA in two reaction volumes of RETROscript (Ambion) using dT primer and then aliquoted for single uses. The primers and fluorescent 
probes for IDE TaqMan real-time PCR were purchased from Applied Biosystems (Foster City, CA) (Assay on Demand \#Mm00473077_m1). The primers for p85 SYBR Green PCR were designed with the Primer Express software (Applied Biosystems) using the mouse p85 $\alpha$ sequence NCBI\#U50413. The primer sequences for p85 were ACCTGTGAACTGAGCTGCAGAA (forward) and TAGAAACGTCTGGTCATCCAACA (reverse). The absence of nonspecific PCR was confirmed by gel electrophoresis using 45-cycle PCR products (data not shown). cDNA for relative standard curves was prepared from $\mathrm{Tg}(-)$ mouse brain with the same protocols with double RNA concentration in the reverse transcription step. Real-time PCR was performed by SDS7700 (Applied Biosystems) with TaqMan Universal PCR Master Mix (Applied Biosystems) for IDE and SYBR Green PCR Master Mix (Applied Biosystems) for p85, using triplicates for samples and quadruplicates for standards. Glyceraldehyde-3-phosphate dehydrogenase (GAPDH) was measured as the internal control using TaqMan Rodent GAPDH control (Applied Biosystems). Consistent GAPDH levels confirm the absence of RNA and/or cDNA degradation (data not shown). The absence of contamination was checked using RT products made without Moloney murine leukemia virus reverse transcriptase. The $R^{2}$ of relative standard curves was $>0.99$. $R^{2}$ of mRNA levels from the same samples but measured on different days was $\sim 0.9$. Despite the great reproducibility and use of the same five points standards in every plate, $\sim 5 \%$ difference in average values between different PCR plates with same samples was observed (data not shown). For optimum reliable comparisons, only sample values from the same PCR plate were analyzed statistically and shown here.

Chemicals. Insulin was obtained from Sigma (St. Louis, MO); wortmannin and LY 294002 were purchased from Calbiochem (La Jolla, CA). Primary antibodies used in this study include anti-IDE (Oncogene Research Products, San Diego, CA), anti-pAkt (Cell Signaling Biotechnologies, Beverly, MA), anti-actin (Chemicon International, Temecula, $\mathrm{CA}$ ), and anti-A $\beta$ (6E10; Signet Laboratories, Dedham, MA). The rabbit IDE antibody purchased from Oncogene Research Products (catalog \#PC730) is produced from a recombinant glutathione $S$-transferase fusion protein containing amino acids $97-273$ of rat IDE. The known species reactivity includes human, mouse, and rat, and it is used for both immunoblotting and immunocytochemistry purposes. Specificity of the IDE antibody was demonstrated by a single $115 \mathrm{kDa}$ band in Western immunoblotting when soluble fractions from human and rat brain and liver were probed with this antibody (Morelli et al., 2003).

Data analysis. Data were presented as group means \pm SEM. Immunoblot data were expressed as the percentage relative to controls (unstimulated cells, normal brains, or Tg2576 mice on standard diet) run in the same experiment or their optical density values. Statistical analysis was performed by one-way ANOVA followed by Fisher's PLSD post hoc analyses.

\section{Results}

\section{Insulin induces IDE upregulation in primary hippocampal neurons}

Because insulin often induces different physiological responses at different doses, we conducted dose-response experiments to determine the appropriate doses to observe insulin-induced IDE changes. Hippocampal neurons were treated with 0.2, 2, 20, 200, and $500 \mathrm{~nm}$ insulin for $24 \mathrm{hr}$, and IDE protein levels were determined. Western immunoblotting data shown in Figure $1 \mathrm{~A}$ indicate that insulin significantly increased IDE protein levels in hippocampal neurons at 20, 200, and $500 \mathrm{nM}(155.81 \pm 14.49 \%$ relative to control at $20 \mathrm{nM}, 167.86 \pm 25.02$ at $200 \mathrm{nM}$, and $157.69 \pm 29.39$ at $500 \mathrm{nM}\left({ }^{*} p \leq 0.05\right) ; 20 \mathrm{~nm}$ was selected for the following mechanistic experiments because it is an effective concentration that produces a near saturation in IDE levels.

The insulin receptor is a heterotetrameric tyrosine kinase receptor. After binding insulin, it undergoes autophosphorylation and subsequently tyrosine phosphorylates insulin receptor substrates, src homology 2 domain-containing and growth factor receptor bound-2 associated binder-1, each of which provides
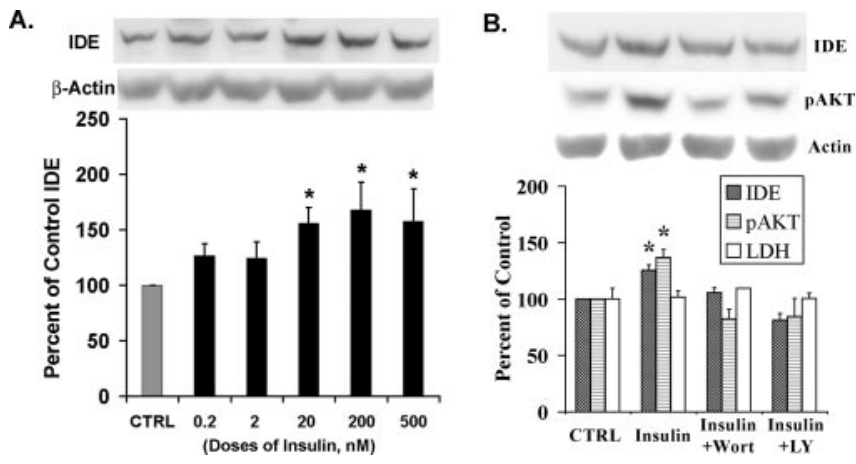

Figure 1. Insulin induces IDE upregulation in primary hippocampal neurons through the $\mathrm{PI}$ kinase-Akt signaling pathway. Hippocampal neurons were treated with different doses of insulin for $24 \mathrm{hr}$, followed by determination of IDE by Western immunoblotting $(A)$. Neurons were then treated with $20 \mathrm{~nm}$ insulin for $24 \mathrm{hr}$ with or without $\mathrm{PI} 3$ kinase inhibitors wortmannin (Wort; $50 \mathrm{~nm}$ ) or LY 294002 (LY; $25 \mu \mathrm{m}$ ), followed by determination of IDE and phospho-Akt levels by Western immunoblotting. LDH release was used as an index for cell viability $(B) .{ }^{*} p \leq$ 0.05 relative to control.

specific docking sites for other signaling molecules. These events lead to activation of phosphatidylinositol-3 (PI3) kinase (Kim et al., 2004). Because PI3 kinase activation is a well recognized consequence of insulin signaling, we determined whether IDE upregulation was through PI3 kinase activation. Two PI3 kinase inhibitors, wortmannin (50 nM) and LY $294002(25 \mu \mathrm{M})$, were used to block PI3 kinase activation. The use of two structurally different inhibitors here rules out the possibility of nonspecific pharmacological effects of the inhibitors. Our results show that both inhibitors blocked insulin-induced IDE upregulation $(105.73 \pm 4.08 \%$ for wortmannin and $81.36 \pm 6.02 \%$ for LY 294002 , relative to control) (Fig. $1 B$ ), suggesting that PI3 kinase is the intermediate molecule mediating insulin-induced IDE expression. To ensure that insulin did activate PI3 kinase and that wortmannin and LY 294002 did in fact block PI3 kinase activation, we determined the activity of PI3 kinase after insulin treatment by determining the levels of pAkt, a downstream target of PI3 kinase activation. As expected, our results confirmed the activation of PI3 kinase by insulin (136.96 $\pm 7.21 \%$ relative to control; $\left.{ }^{\star} p \leq 0.05\right)$ and showed that the wortmannin and LY 294002 were indeed PI3 kinase blockers in our experiments (Fig. $1 B$ ).

To ensure that the abolishment of insulin-induced IDE upregulation by $\mathrm{PI} 3$ kinase inhibitors is not caused by compromised cell survival, LDH release was measured in the neuronal media. No significant differences in LDH release among the different treatment groups were observed (Fig. $1 B$ ), indicating that insulin effects on IDE and PI3 kinase were not caused by changes in cell viability. Also, our primary neuronal cultures are predominantly terminally differentiated and nondividing. To confirm that the protein changes in response to insulin treatment were not caused by increased cell number, for example, from stem cells, we quantified actin levels, which were equal among the four treatment groups.

The Western blot data on insulin-induced IDE upregulation and PI3 kinase activation were further supported by our immunocytochemical staining results. Figure 2 indicates that insulin increased the intensity of cytoplasmic IDE immunofluorescence per cell in hippocampal neurons ${ }^{*} p \leq 0.05$ relative to control levels) (Fig. 2), suggesting an insulin-induced increase in IDE expression. Consistent with the Western blot results, the per cell IDE and pAkt increases induced by insulin did not occur in the presence of either wortmannin or LY 294002, using doses that did not impact neuronal number, as measured by DAPI-positive neuronal nuclei (Fig. 2). 

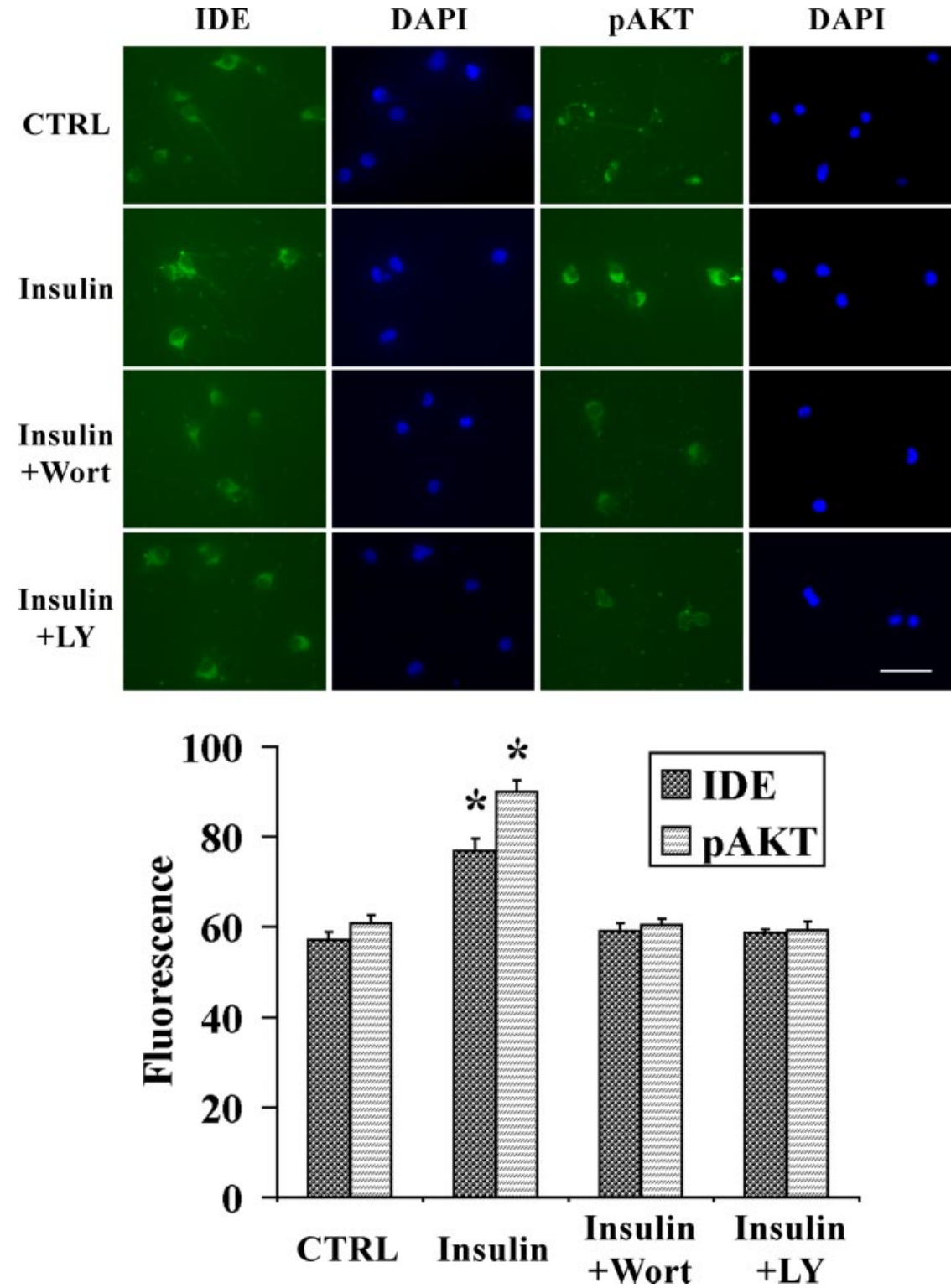

Figure 2. Immunocytochemical images showing insulin-induced IDE upregulation and PI3 kinase activation in vitro in primary hippocampal neurons. Hippocampal neurons were treated with $20 \mathrm{~nm}$ insulin with or without PI3 kinase inhibitors wortmannin (Wort; $50 \mathrm{~nm}$ ) or LY 294002 (LY; $25 \mu \mathrm{m}$ ) for $24 \mathrm{hr}$, followed by determination of IDE and phospho-Akt levels by immunocytochemical staining. DAPI was used to stain neuronal nuclei. NIH Image software was used to quantify the fluorescence. Scale bar, $50 \mu \mathrm{m}$. ${ }^{*} p \leq 0.05$ relative to control.

\section{Correlation of PI3 kinase (p85) and IDE in human brains}

Because one of the pathological hallmarks of $\mathrm{AD}$ is increased amyloid plaques composed of aggregated $\mathrm{A} \beta$, we investigated whether IDE was decreased in AD brains and whether the decreased IDE was correlated with the levels of PI3 kinase. Levels of p85, a subunit of PI3 kinase, were determined as an index for the levels of PI3 kinase. Hippocampus (Fig. $3 A$ ) and temporal cortex (Fig. $3 B$ ) were obtained from normal and AD brains, and IDE and p85 levels were determined. Both IDE and p85 were decreased in AD hippocampus (73.52 $\pm 6.29 \%$ for IDE and $65.83 \pm 6.13 \%$ for p85; ${ }^{\star} p \leq 0.05$ relative to levels in normal) and AD temporal cortex $\left(70.95 \pm 6.96 \%\right.$ for IDE and $42.39 \pm 6.95 \%$ for $\mathrm{p} 85 ;{ }^{\star} p \leq$ 0.05 relative to levels in normal) (Fig. $3 A, B$ ).

To determine the relationship between IDE and p85, we ran a correlation between them and found that IDE and p85 levels were significantly correlated in both the hippocampus $\left(R^{2}=0.43 ; p \leq\right.$
$0.001)$ and temporal cortex $\left(R^{2}=0.25 ; p \leq\right.$ 0.01 ), providing an in vivo support for the relevance of the causal relationship between PI3 kinase and IDE demonstrated in vitro (Fig. 3A,B).

The reduction of IDE and p85 was found to be specific in AD brains because other proteins, such as SNAP25 (soluble $\mathrm{N}$-ethylmaleimide-sensitive factor attachment protein 25) and neuron-specific enolase, were not changed in $\mathrm{AD}$ brains (data not shown). A trend of synaptophysin decrease was observed in $\mathrm{AD}$ brains, but the effect was not significant. Selective neuron loss occurs in temporal cortex, but measures of global neuron loss, for example, loss of neurofilament positive neurons, was not seen when $\mathrm{AD}$ and control cortex were compared (Shepherd et al., 2001). We also stained our own set of normal and $\mathrm{AD}$ temporal cortex with cresyl violet and saw no obvious difference in total neuronal number, indicating that the reduced expression of IDE and PI3 kinase in $\mathrm{AD}$ was not likely caused solely by the reduced number of neurons (data not shown). Also, because postsynaptic density-95 (PSD-95) was also significantly downregulated in AD brains, the correlation between IDE and PSD-95 was determined, and no significant correlation was observed between them $\left(R^{2}=0.001\right.$ in hippocampus and $R^{2}=0.002$ in temporal cortex), suggesting that the correlation between IDE and p85 levels in human brains was not simply secondary to mutual loss, but more specific. Interestingly, when the IDE levels were analyzed based on apolipoprotein $\mathrm{E}$ (ApoE) genotype, we found that patients with two copies of ApoE4 had the lowest IDE levels, followed by those with one copy of ApoE4, and the highest IDE levels were seen in the human subjects without ApoE4 (Fig. 3C,D). This is consistent with the results of Cook et al. (2003) which found that IDE levels are reduced by up to $50 \%$ in ApoE4+ human subjects compared with ApoE4- subjects.

\section{Correlation of insulin signaling and IDE in an AD animal model}

Mice on a high-fat diet exhibit decreased insulin signaling and decreased IDE levels, supporting their physiological link in an AD animal model (Ho et al., 2004). Also, Tg2576 Swedish amyloid precursor protein mutant mice raised on a diet substituting soy and fish oil fat in standard PMI 5015 chow with 6\% safflower oil as the source of fat (Bad diet) have been shown by our laboratory to possess a number of $\mathrm{AD}$-related postsynaptic deficits, which serve as an improved animal model for AD pathology (Calon et al., 2004). We therefore compared the levels of IDE and p85 in mice fed the standard diet and the Bad diet. Similar to what is occurring in AD brains, both IDE and p85 mRNAs were de- 
A. Hippocampus
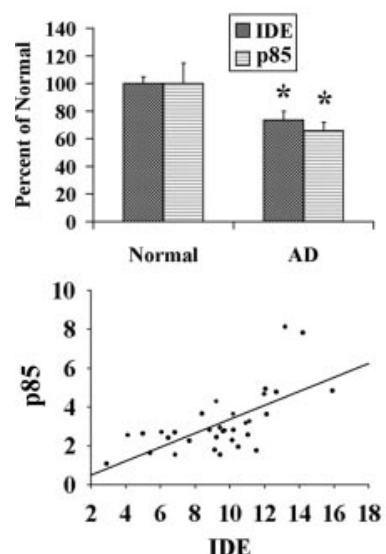

C. IDE values in Hippocampus

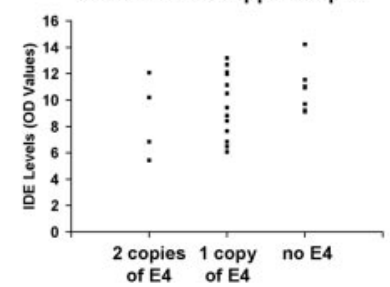

B. Temporal Cortex

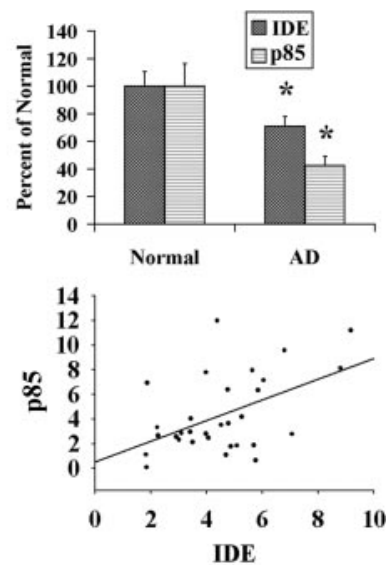

D.

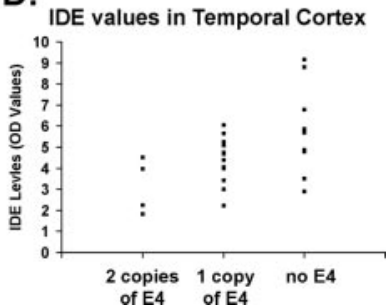

Figure 3. Both IDE and p85 (a PI3 kinase subunit) were decreased in the hippocampus $(A)$ and temporal cortex $(B)$ of AD brains compared with normal brains. IDE and p85 levels were significantly correlated in both hippocampus and temporal cortex, providing an in vivo support for the causal relationship between PI3 kinase and IDE. ${ }^{*} p \leq 0.05$ relative to normal. IDE levels in the hippocampus $(C)$ and temporal cortex $(D)$ were also plotted against the number of copies of ApoE4 in the human subjects.

creased in Bad diet-fed animals (71.59 $\pm 5.34 \%$ for IDE and $68.01 \pm 3.83 \%$ for $\mathrm{p} 85 ;{ }^{\star} p \leq 0.05$ relative to mice on standard diet), and the mRNA levels of IDE and p85 were significantly correlated $\left(R^{2}=0.51 ; p \leq 0.01\right)$ (Fig. $4 A$ ). Similarly, protein levels of IDE and p85 were reduced in Bad diet-fed mice (27.85 \pm $20.33 \%$ for IDE and $2.27 \pm 1.84 \%$ for $\mathrm{p} 85 ;{ }^{\star} p \leq 0.05$ relative to mice on standard diet), and the protein levels of IDE and p85 were also significantly correlated $\left(R^{2}=0.43 ; p \leq 0.01\right)$ (Fig. $\left.4 A\right)$. It is noteworthy, however, that the loss in p 85 and IDE in the Bad diet-fed mice and their correlation were selective and specific; for example, levels of synaptophysin were not changed in these mice (Calon et al., 2004), and although drebrin, a postsynaptic molecule, was also decreased in mice on the Bad diet (Calon et al., 2004), there was no significant correlation between the levels of IDE and drebrin.

Because IDE has been demonstrated to be a degrading enzyme for $\mathrm{A} \beta$ monomer, we determined the functional consequence of the decreased PI3 kinase and IDE levels in Bad diet-fed mice by measuring $A \beta$ monomer levels in these mice with Western immunoblotting and 6E10 A $\beta$ antibody. Not surprisingly, in the $\mathrm{Bad}(\mathrm{B})$ diet-fed mice, the $\mathrm{A} \beta$ monomer levels were significantly increased compared with animals raised on standard $(S)$ diet $\left.{ }^{*} p \leq 0.05\right)$ (Fig. $4 B$ ). Furthermore, levels of IDE and A $\beta$ monomer in Tg2576 mice were significantly and inversely correlated $\left(R^{2}=0.61 ; p \leq 0.001\right)$, suggesting that the increase in $\mathrm{A} \beta$ monomer in Bad diet-fed mice was related to the decrease in IDE.

\section{Discussion}

In the present study, we used both in vitro and in vivo strategies to determine the regulation of IDE levels by insulin signaling. The

A.

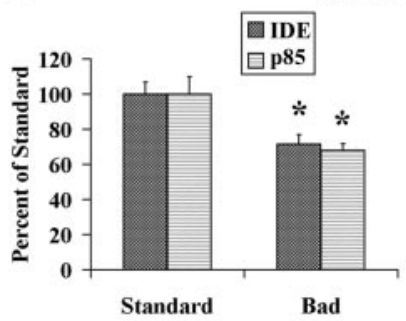

mRNA Levels

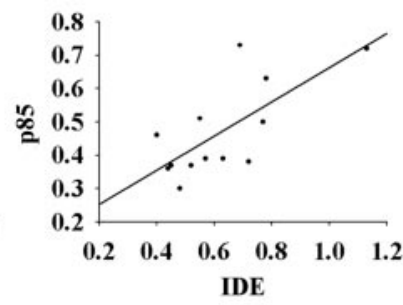

Protein Levels
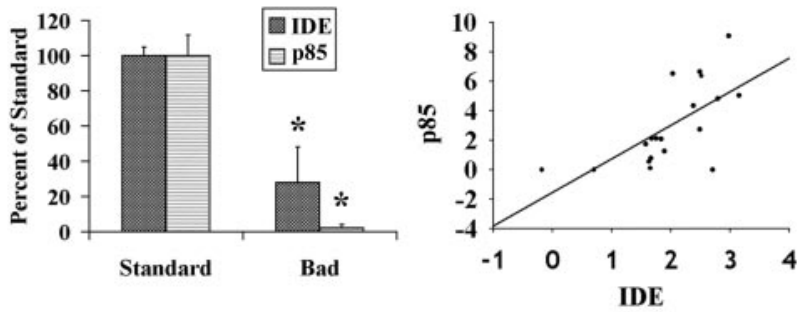

B.
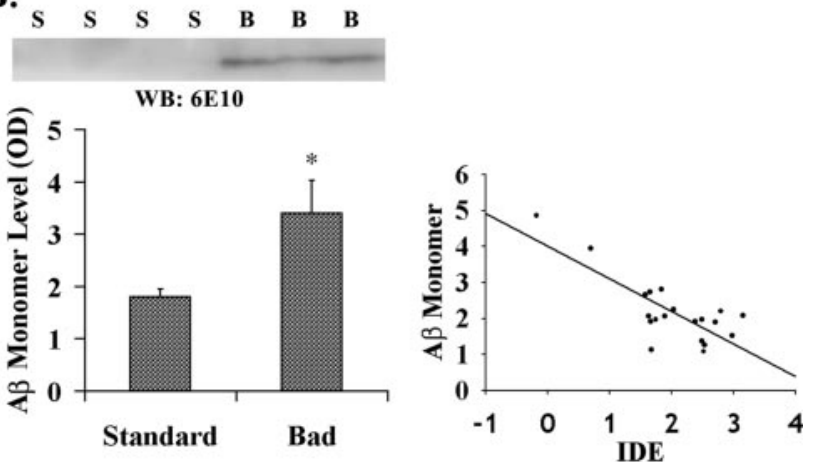

Figure 4. Both IDE and p 85 mRNA and protein levels were decreased in Tg2576 transgenic mice raised with safflower oil-based (Bad) diet compared with mice on standard diet, and the mRNA and protein levels of IDE and $p 85$ were significantly correlated $(A)$. In the Bad $(B)$ diet-fed mice, the $A \beta$ monomer levels were significantly increased compared with animals raised on standard $(S)$ diet, and the levels of $A \beta$ monomer and IDE were significantly inversely correlated, supporting the significance of IDE in $A \beta$ degradation $(B) .{ }^{*} p \leq 0.05$ relative to standard.

results from this study indicate that insulin signaling induced a modest but significant upregulation of IDE, which was abolished by inhibition of the insulin-signaling mediator, PI3 kinase. Our data on $\mathrm{AD}$ and Tg2576 brains were provided as in vivo evidence for the causal relationship between insulin signaling and IDE. Overall, these results suggest that strategies to enhance insulin signaling could be used as an intervention for $\mathrm{AD}$. It is noteworthy, in addition, that although IDE is a degrading enzyme for insulin, enhancing insulin signaling to increase IDE would circumvent the problem of decreased insulin neurotrophic effects caused by upregulated IDE.

$\mathrm{A} \beta$ has been shown to decrease PI3 kinase activity (Takashima et al., 1996), which according to our finding would decrease IDE levels and in turn increase $\mathrm{A} \beta$ levels, thus creating a vicious cycle. Therefore, stimulating the insulin signaling and increasing PI3 kinase activity would break this cycle and reduce the accumulation of $\mathrm{A} \beta$.

The effect of insulin on IDE upregulation is $\sim 25-50 \%$, a modest effect, suggesting a modulatory effect of insulin on the expression of its degrading enzyme. IDE upregulation by insulin signaling, therefore, could be used to bring the IDE to the normal physiological levels and correct the IDE defects in $\mathrm{AD}$, thus re- 
ducing the risk of $\mathrm{A} \beta$ accumulation. Also, IDE is not only a proteolytic degrading enzyme for insulin and $\mathrm{A} \beta$, but also for a number of other peptides such as glucagon (Kirschner and Goldberg, 1983), $\beta$-endorphin, and dynorphins (Safavi et al., 1996). It is interesting to note that both $\mathrm{AD}$ and Down syndrome patients show significant elevations of dynorphins in the frontal cortex tissue (Risser et al., 1996), suggesting that IDE correction by insulin signaling in $\mathrm{AD}$ could also bring down other substrates that are abnormally high.

Our finding of the correlation between insulin signaling and IDE levels is consistent with the Ho et al. (2004) study, which demonstrated a simultaneous decrease in insulin signaling and IDE levels in Tg2576 mice on a high-fat diet. Because our diet is not an established high-fat dietary regimen that induces diabetes, we would not predict that it would induce peripheral insulin resistance as in the Ho et al. (2004) study. In fact, when different levels of a safflower oil diet (10,20, 30, 40,50, and 60\% calories as fat) were fed to C57 female mice for 15 weeks, a significant deterioration of glucose tolerance was observed only in diets of $>40 \%$ fat (Takahashi et al., 1999). Because our Bad diet has only $6 \%$ total fat, which is translated into $\sim 15 \%$ calories as fat, it is well below the $40 \%$ level that induces peripheral insulin resistance. Therefore, there is no reason to predict that peripheral insulin resistance would occur on the $6 \%$ fat Bad diet, and the PI3 kinase pathway deficit occurring in the Bad diet-fed mice appears likely attributable to brain-specific diet and transgene interaction (Calon et al., 2004).

We also have to point out that although the IDE linkage to AD has been shown by a number of laboratories, there are some contradictory reports. For example, Abraham et al. (2001) found no significant association between any individual single nucleotide polymorphism in the IDE gene and AD. The controversy involved with these findings could be the result of differences in the human subjects used. Whatever the cause of variance in the genetic linkage findings, they do not discount the fact that IDE can degrade $A \beta$ nor do they subtract from the significance of our observations that enhanced insulin signaling could be used to upregulate IDE to degrade the pathogenetic $\mathrm{A} \beta$.

\section{Increased risk of $\mathrm{AD}$ in insulin-resistant diabetes mellitus}

$\mathrm{AD}$ is characterized by three pathological hallmarks: amyloid plaques composed of aggregated $\mathrm{A} \beta$, fibrillar tangles made of hyperphosphorylated tau, and synaptic defects leading to neuritic dystrophy and neuronal death. Increasing epidemiological evidence has demonstrated that type II diabetes mellitus is a potent risk factor for developing $\mathrm{AD}$. Insulin resistance observed in diabetes has been shown to be linked to the AD pathological hallmarks described above. For example, in the diabetic mice used in the Ho et al. (2004) study, insulin resistance was associated with significant accumulation of $\mathrm{A} \beta$ and amyloid plaque burden at 9 months, as well as significant downregulation of phosphorylated glycogen synthase kinase 3, which leads to significant tau pathologies (Ho et al., 2004). Because IDE degrades monomeric $\mathrm{A} \beta$ and our Tg2576 study began at 17-19 months after plaques are well established (Kawarabayashi et al., 2001), we did not pursue the plaque endpoint but focused instead on monomer. A recent longitudinal cohort study reported that diabetes mellitus significantly increases the risk of developing AD by $65 \%$ (Arvanitakis et al., 2004). In addition, diabetes mellitus was associated with lower levels of cognition and memory (Arvanitakis et al., 2004). Retrospective studies reported an increased incidence of AD in diabetic subjects (Leibson et al., 1997). Furthermore, the increased risk for developing $\mathrm{AD}$ is independent of its vascular effect, because when the vascular risk factors are controlled, the increased risk of $\mathrm{AD}$ remains strong (Grossman, 2003). Insulin resistance and defective insulin signaling are the principal characteristics of type II diabetes mellitus. Insulin resistance, therefore, appears as a potent accelerator of AD risks. Results reported in the current study suggest that one of the underlying mechanisms for the increased $\mathrm{AD}$ risk in diabetic subjects is chronically reduced IDE levels. The decreased IDE levels would cause increased A $\beta$ monomer; although $\mathrm{A} \beta$ monomer per se has been shown to exert beneficial effects such as antioxidant and trophic effects (Smith et al., 2002), pushing the $\mathrm{A} \beta$ monomer-oligomer-fibril equilibrium forward would accelerate the formation of toxic oligomers. Also, consistent with Cook et al. (2003), we found that ApoE4+ AD patients have less IDE than those with no ApoE4 allele. Combined with the saturable IDE response to insulin, this result may shed light on the finding that ApoE4 $+\mathrm{AD}$ patients who have lower IDE and a larger range for an IDE response are more sensitive to insulin treatment-induced memory improvement than ApoE3/3 patients (Craft et al., 2003). With regard to the factors contributing to decreased insulin signaling, it is noteworthy that genetically determined defects in insulin signaling have been found to be linked to $\mathrm{AD}$ risk; for example, a p85 subunit polymorphism showed linkage to late-onset AD (Liolitsa et al., 2002). Besides genetic factors, reduced brain insulin levels can be caused by peripheral insulin resistance through a high-fat diet (Kaiyala et al., 2000). Also, although in our current study the n-3 unsaturated fatty acid-depleted Bad diet does not appear likely to cause peripheral insulin resistance, it contributes to reduced insulin signaling in the brain through downregulation of $\mathrm{p} 85$.

\section{Significance of enhancing insulin signaling in AD therapeutics}

The increased odds of AD in diabetic subjects, together with the positive impact of insulin on cognition and memory as discussed above, suggest that enhancement of insulin signaling could be used as an intervention strategy for AD. In fact, a number of studies support this hypothesis. Craft et al. (1998) determined the plasma and CSF insulin levels in $\mathrm{AD}$ and control subjects and found that $\mathrm{AD}$ patients had lower CSF insulin, higher plasma insulin, and a reduced CSF to plasma insulin ratio when compared with healthy adults. The differences were greater for patients with more advanced AD (Craft et al., 1998). Subsequent clinical studies by the same group showed that hyperinsulinemia with fasting glucose levels achieved by insulin and variable dextrose infusion into $\mathrm{AD}$ patients resulted in improved memory relative to placebo (Craft et al., 1999). Conversely, intracerebroventricular injection of streptozotocin caused long-term and progressive deficits in learning and memory as well as biochemical changes and neuronal degeneration in rats similar to those in AD (Grunblatt et al., 2004).

Although activation of insulin signaling may be ideal for AD therapeutics, insulin per se is not the ideal molecule. Although insulin can induce a signaling pathway leading to IDE upregulation, it competes with $\mathrm{A} \beta$ for available IDE. This is consistent with a recent study that insulin infusion causes increased CSF A $\beta 42$ levels in subjects $>70$ years of age (Watson et al., 2003). Other problems with insulin use include hypoglycemia, which could worsen memory and cognition in $\mathrm{AD}$ patients. In fact, systemic insulin administration has been associated with memory deficits, likely caused in part by hypoglycemia that occurs when exogenous insulin is not supplemented with glucose to maintain endogenous glucose levels (Watson and Craft, 2004). Therefore, insulin receptor modulators that are not a substrate of IDE, and preferably act in the CNS, should be investigated for 
their potential preventive and therapeutic effects on AD pathology. Our data on the Bad diet-fed mice also suggest that dietary fat is a candidate to impact the insulin signaling. In summary, because enhanced insulin signaling may help to correct neuron defects in $\mathrm{AD}$ and can also reduce $\mathrm{A} \beta$ monomer, this may be a crucial strategy for AD intervention.

\section{References}

Abraham R, Myers A, Wavrant-DeVrieze F, Hamshere ML, Thomas HV, Marshall H, Compton D, Spurlock G, Turic D, Hoogendoorn B, Kwon JM, Petersen RC, Tangalos E, Norton J, Morris JC, Bullock R, Liolitsa D, Lovestone S, Hardy J, Goate A, et al. (2001) Substantial linkage disequilibrium across the insulin-degrading enzyme locus but no association with late-onset Alzheimer's disease. Hum Genet 109:646-652.

Arvanitakis Z, Wilson RS, Bienias JL, Evans DA, Bennett DA (2004) Diabetes mellitus and risk of Alzheimer disease and decline in cognitive function. Arch Neurol 61:661-666.

Bertram L, Blacker D, Mullin K, Keeney D, Jones J, Basu S, Yhu S, McInnis MG, Go RC, Vekrellis K, Selkoe DJ, Saunders AJ, Tanzi RE (2000) Evidence for genetic linkage of Alzheimer's disease to chromosome 10q. Science 290:2302-2303.

Boyd Jr FT, Raizada MK (1983) Effects of insulin and tunicamycin on neuronal insulin receptors in culture. Am J Physiol 245:C283-C287.

Calon F, Lim GP, Yang F, Morihara T, Teter B, Ubeda O, Rostaing P, Triller A, Salem Jr N, Ashe KH, Frautschy SA, Cole GM (2004) Docosahexaenoic acid protects from dendritic pathology in an Alzheimer's disease mouse model. Neuron 43:633-645.

Cook DG, Leverenz JB, McMillan PJ, Kulstad JJ, Ericksen S, Roth RA, Schellenberg GD, Jin LW, Kovacina KS, Craft S (2003) Reduced hippocampal insulin-degrading enzyme in late-onset Alzheimer's disease is associated with the apolipoprotein E-epsilon4 allele. Am J Pathol 162:313-319.

Craft S, Peskind E, Schwartz MW, Schellenberg GD, Raskind M, Porte Jr D (1998) Cerebrospinal fluid and plasma insulin levels in Alzheimer's disease: relationship to severity of dementia and apolipoprotein E genotype. Neurology 50:164-168.

Craft S, Asthana S, Newcomer JW, Wilkinson CW, Matos IT, Baker LD, Cherrier M, Lofgreen C, Latendresse S, Petrova A, Plymate S, Raskind M, Grimwood K, Veith RC (1999) Enhancement of memory in Alzheimer disease with insulin and somatostatin, but not glucose. Arch Gen Psychiatry 56:1135-1140.

Craft S, Asthana S, Cook DG, Baker LD, Cherrier M, Purganan K, Wait C, Petrova A, Latendresse S, Watson GS, Newcomer JW, Schellenberg GD, Krohn AJ (2003) Insulin dose-response effects on memory and plasma amyloid precursor protein in Alzheimer's disease: interactions with apolipoprotein E genotype. Psychoneuroendocrinology 28:809-822.

Ertekin-Taner N, Graff-Radford N, Younkin LH, Eckman C, Baker M, Adamson J, Ronald J, Blangero J, Hutton M, Younkin SG (2000) Linkage of plasma Abeta 42 to a quantitative locus on chromosome 10 in late-onset Alzheimer's disease pedigrees. Science 290:2303-2304.

Ertekin-Taner N, Allen M, Fadale D, Scanlin L, Younkin L, Petersen RC, Graff-Radford N, Younkin SG (2004) Genetic variants in a haplotype block spanning IDE are significantly associated with plasma Abeta42 levels and risk for Alzheimer disease. Hum Mutat 23:334-342.

Farris W, Mansourian S, Chang Y, Lindsley L, Eckman EA, Frosch MP, Eckman CB, Tanzi RE, Selkoe DJ, Guenette S (2003) Insulin-degrading enzyme regulates the levels of insulin, amyloid beta-protein, and the betaamyloid precursor protein intracellular domain in vivo. Proc Natl Acad Sci USA 100:4162-4167.

Farris W, Mansourian S, Leissring MA, Eckman EA, Bertram L, Eckman CB, Tanzi RE, Selkoe DJ (2004) Partial loss-of-function mutations in insulin-degrading enzyme that induce diabetes also impair degradation of amyloid beta-protein. Am J Pathol 164:1425-1434.

Grossman H (2003) Does diabetes protect or provoke Alzheimer's disease? Insights into the pathobiology and future treatment of Alzheimer's disease. CNS Spectr 8:815-823.

Grunblatt E, Hoyer S, Riederer P (2004) Gene expression profile in streptozotocin rat model for sporadic Alzheimer's disease. J Neural Transm 111:367-386.

Ho L, Qin W, Pompl PN, Xiang Z, Wang J, Zhao Z, Peng Y, Cambareri G, Rocher A, Mobbs CV, Hof PR, Pasinetti GM (2004) Diet-induced insulin resistance promotes amyloidosis in a transgenic mouse model of Alzheimer's disease. FASEB J 18:902-904.
Kaiyala KJ, Prigeon RL, Kahn SE, Woods SC, Schwartz MW (2000) Obesity induced by a high-fat diet is associated with reduced brain insulin transport in dogs. Diabetes 49:1525-1533.

Kawarabayashi T, Younkin LH, Saido TC, Shoji M, Ashe KH, Younkin SG (2001) Age-dependent changes in brain, CSF, and plasma amyloid $\beta$ protein in the $\mathrm{Tg} 2576$ transgenic mouse model of Alzheimer's disease. J Neurosci 21:372-381.

Kim B, van Golen CM, Feldman EL (2004) Insulin-like growth factor-I signaling in human neuroblastoma cells. Oncogene 23:130-141.

Kirschner RJ, Goldberg AL (1983) A high molecular weight metalloendoprotease from the cytosol of mammalian cells. J Biol Chem 258:967-976.

Leibson CL, Rocca WA, Hanson VA, Cha R, Kokmen E, O’Brien PC, Palumbo PJ (1997) The risk of dementia among persons with diabetes mellitus: a population-based cohort study. Ann NY Acad Sci 826:422-427.

Lim GP, Chu T, Yang F, Beech W, Frautschy SA, Cole GM (2001) The curry spice curcumin reduces oxidative damage and amyloid pathology in an Alzheimer transgenic mouse. J Neurosci 21:8370-8377.

Liolitsa D, Powell J, Lovestone S (2002) Genetic variability in the insulin signaling pathway may contribute to the risk of late onset Alzheimer's disease. J Neurol Neurosurg Psychiatry 73:261-266.

Morelli L, Llovera R, Gonzalez SA, Affranchino JL, Prelli F, Frangione B, Ghiso J, Castano EM (2003) Differential degradation of amyloid beta genetic variants associated with hereditary dementia or stroke by insulindegrading enzyme. J Biol Chem 278:23221-23226.

Olson DE, Norris SL (2004) Diabetes in older adults. Overview of AGS guidelines for the treatment of diabetes mellitus in geriatric populations. Geriatrics 59:18-24.

Ott A, Stolk RP, Hofman A, van Harskamp F, Grobbee DE, Breteler MM (1996) Association of diabetes mellitus and dementia: the Rotterdam study. Diabetologia 39:1392-1397.

Ott A, Stolk RP, van Harskamp F, Pols HA, Hofman A, Breteler MM (1999) Diabetes mellitus and the risk of dementia: the Rotterdam study. Neurology 53:1937-1942.

Peila R, Rodriguez BL, Launer LJ (2002) Type 2 diabetes, APOE gene, and the risk for dementia and related pathologies: the Honolulu-Asia aging study. Diabetes 51:1256-1262.

Risser D, You ZB, Cairns N, Herrera-Marschitz M, Seidl R, Schneider C, Terenius L, Lubec G (1996) Endogenous opioids in frontal cortex of patients with Down syndrome. Neurosci Lett 203:111-114.

Safavi A, Miller BC, Cottam L, Hersh LB (1996) Identification of gammaendorphin-generating enzyme as insulin-degrading enzyme. Biochemistry 35:14318-14325.

Shepherd CE, Thiel E, McCann H, Halliday GM (2001) Neurofilamentimmunoreactive neurons are not selectively vulnerable in Alzheimer's disease. Neurobiol Dis 8:136-146.

Smith MA, Casadesus G, Joseph JA, Perry G (2002) Amyloid-beta and tau serve antioxidant functions in the aging and Alzheimer brain. Free Radic Biol Med 33:1194-1199.

Takahashi M, Ikemoto S, Ezaki O (1999) Effect of the fat/carbohydrate ratio in the diet on obesity and oral glucose tolerance in C57BL/6J mice. J Nutr Sci Vitaminol (Tokyo) 45:583-593.

Takashima A, Noguchi K, Michel G, Mercken M, Hoshi M, Ishiguro K, Imahori K (1996) Exposure of rat hippocampal neurons to amyloid beta peptide (25-35) induces the inactivation of phosphatidyl inositol-3 kinase and the activation of tau protein kinase I/glycogen synthase kinase-3 beta. Neurosci Lett 203:33-36.

Vekrellis K, Ye Z, Qiu WQ, Walsh D, Hartley D, Chesneau V, Rosner MR, Selkoe DJ (2000) Neurons regulate extracellular levels of amyloid $\beta$-protein via proteolysis by insulin-degrading enzyme. J Neurosci 20:1657-1665.

Watson GS, Craft S (2004) Modulation of memory by insulin and glucose: neuropsychological observations in Alzheimer's disease. Eur J Pharmacol 490:97-113.

Watson GS, Peskind ER, Asthana S, Purganan K, Wait C, Chapman D, Schwartz MW, Plymate S, Craft S (2003) Insulin increases CSF Abeta42 levels in normal older adults. Neurology 60:1899-1903.

Zahniser NR, Goens MB, Hanaway PJ, Vinych JV (1984) Characterization and regulation of insulin receptors in rat brain. J Neurochem 42:1354-1362.

Zhao L, Chen S, Brinton RD (2003) An estrogen replacement therapy containing nine synthetic plant-based conjugated estrogens promotes neuronal survival. Exp Biol Med 228:823-835. 